\title{
Impactos técnico-econômicos da adubação de pastos
}

\author{
Carlos Eduardo Avelino CABRAL ${ }^{1 *}$, Carla Heloisa Avelino CABRAL ${ }^{1}$, \\ Alyce Raiana Monteiro SANTOS², Aline Müller MOTTA¹, Lucas Gimenes MOTA³
}

\begin{abstract}
${ }^{1}$ Instituto de Ciências Agrárias e Tecnológicas, Universidade Federal de Rondonópolis, Rondonópolis, MT, Brasil.
${ }^{2}$ Centro de Energia Nuclear na Agricultura, Universidade de São Paulo, Piracicaba, SP, Brasil.

${ }^{3}$ Faculdade de Agronomia e Zootecnia, Universidade Federal de Mato Grosso, Cuiabá, MT, Brasil

*E-mail: carlos.eduardocabral@hotmail.com

(Orcid: 0000-0002-8318-9552; 0000-0002-5385-1947; 0000-0002-1049-7597;
\end{abstract}

0000-0003-1856-822X; 0000-0003-2820-8922)

Recebido em 06/04/2021; Aceito em 10/05/2021; Publicado em 14/05/2021.

\begin{abstract}
RESUMO: A criação de bovinos no Brasil ocorre, prioritariamente, em pastagens e, neste contexto, a adubação do pasto é uma importante estratégia de aumento na eficiência produtiva. Diante disso, objetivou-se, com esta revisão, descrever os impactos técnicos da adubação no desenvolvimento de gramíneas tropicais. A calagem é uma prática importante na disponibilidade dos nutrientes e, novos estudos visam demonstrar que o intervalo entre a incorporação do calcário e a semeadura tem maior dependência da umidade do solo e que é possível reduzir este período que tradicionalmente é de 60 a 90 dias. A adubação fosfatada tem maior impacto sobre a implantação do que a manutenção do pasto, e quando negligenciada na formação do pasto, observa-se um efeito residual sobre a rebrota. O nitrogênio e o potássio são os nutrientes mais extraídos na manutenção dos pastos, o que se torna importante o estudo da relação entre estes nutrientes, bem como a adoção da adubação potássica em sistemas em que a adubação nitrogenada é uma prática rotineira. A varredura, que consiste na mistura de sobras de fertilizantes em galpões, embora tenha baixo custo por quilo de produto, o uso pode ser antieconômico, o que depende da composição do insumo adquirido.
\end{abstract}

Palavras-chave: calagem; fertilização de pastos; formação de pastagens.

\section{Technical and economic impacts of pasture fertilization}

\begin{abstract}
Cattle production on Brazil priority occurs in grasslands, in this context, pasture fertilization is an important strategy to improve production efficiency. Therefore, the aim with this review is to describe the technical impacts of fertilization on tropical grass development. Liming is an important practice in nutrient availability and new studies aim to demonstrate that the interval between limestone incorporation and seeding has more dependence on soil moisture, and that is possible to reduce this period, which traditionally is from 60 to 90 days. Phosphate fertilization has a greater impact on pasture implantation than maintenance, and when neglected in pasture formation, there is a residual effect on regrowth. Nitrogen and potassium are the nutrients extracted on pasture maintenance, which makes it important to study the relationship between these nutrients, as well as the adoption of potassium fertilization in systems where nitrogen fertilization is a routine practice. Mixing leftover fertilizers in warehouses, although it has a low cost per kilo of product, the use can be uneconomical, which depends on the input composition purchased.
\end{abstract}

Keywords: liming; pasture fertilization; pasture implantation.

\section{INTRODUÇÃO}

Em 2019, a pecuária de corte representou 8,5\% do PIB brasileiro (ABIEC, 2020), o que demonstra a importância desta atividade para a economia brasileira. $\mathrm{Na}$ bovinocultura de corte, a maior parte dos animais são criados exclusivamente em pastagens, principalmente, em lotação contínua com baixo controle do manejo do pastejo e sem reposição periódica de nutrientes, o que acelera o processo de degradação.

Um agravante do processo de degradação dos pastos é que grande parte da pecuária de corte ocorre em Latossolos, que são solos de elevada acidez, baixo teor de fósforo e bases, o que requer reposição de nutrientes para manutenção do potencial produtivo (ALMEIDA et al., 2021). Todavia, a adubação não é demanda exclusiva de solos de baixa fertilidade, pois evidencia-se o processo de degradação mesmo em solos com elevado teor de nutrientes. Nestes casos, o principal nutriente requerido é o nitrogênio, pois não provém do material de origem do solo (rocha) e inclusive, a ausência de nitrogênio é uma das principais causas da degradação de pastagens.

Dessa forma, a adubação é uma prática muito relevante para manutenção produtiva das pastagens, entretanto, o uso racional de fertilizantes exige a identificação dos nutrientes prioritários para uso em implantação e manutenção das pastagens. Além disso, deve-se realizar avaliação contínua da viabilidade econômica, visto que os fertilizantes aumentam o custo de produção do sistema.

Além da perspectiva econômica, a falta de planejamento no uso de fertilizantes tem impacto ambiental, pois as principais matérias-primas utilizadas para obtenção de corretivos e fertilizantes provém de rochas (calcário, fertilizantes fosfatados e potássicos) ou utilizam petróleo ou derivados na fabricação (fertilizantes nitrogenados), que são 
insumos provenientes de ciclo geológico para formação, o que pode tornar o sistema não sustentável em longo prazo. Por isso, o planejamento da adubação das pastagens é essencial para garantir uma futura pecuária de corte, bem como promover melhoria dos sistemas atuais, como o aumento de produtividade de sistemas extensivos e promover ajustes em sistemas intensificados, sem desprezar a viabilidade econômica.

\section{REVISÃO DE LITERATURA}

2.1. Uso de calcário para formação e manutenção de pastagens

O calcário é um importante insumo utilizado, principalmente, para correção da acidez do solo. Este insumo reduz o teor de alumínio tóxico no solo, aumenta a capacidade de troca catiônica (CTC), a mineralização da matéria-orgânica e a eficiência da adubação fosfatada (MORTON, 2018). Por isso, deve-se utilizar calcário para formação de pastagens em solos com baixa saturação de bases e elevada saturação de alumínio.

No estabelecimento, o calcário deve ser incorporado antes da semeadura, tendo em vista que há baixa mobilidade deste insumo no solo (DA COSTA; CRUSCIOL, 2016). Além disso, para que o calcário neutralize o alumínio tóxico e aumente o pH do solo é necessário a presença de água, por isso, a aplicação de calcário deve ser realizada no início do período chuvoso.
A disponibilidade hídrica no solo necessária para reagir o calcário no solo é mais importante que o próprio intervalo entre a calagem e a semeadura. $\mathrm{Na}$ prática, os produtores aguardam o intervalo de 60 a 90 dias entre a incorporação do calcário e a semeadura, entretanto, por meio de pesquisas será possível ajustar o intervalo conforme a disponibilidade hídrica do solo.

Ao realizar a análise de solo 45 dias após a incorporação do calcário, observou-se que aumentar a umidade do solo, uma única vez, para a máxima capacidade de retenção de água foi suficiente para zerar uma saturação de alumínio inicial de 75\% (MELO et al., 2019) e proporcionar o estabelecimento adequado do capim BRS Ipyporã (Brachiaria brizantha $\mathrm{x}$ Brachiaria ruziz̨iensis) (Tabela 1).

Em situações em que o calcário tenha que ser aplicado na entressafra (período sem chuva), o que é comum em propriedades rurais que realizam sistemas integrados de produção agropecuária, a semeadura da gramínea somente poderá ser realizada no início do período chuvoso se o solo estiver com a saturação de bases adequada. Caso contrário, o alumínio trivalente irá precipitar o fósforo aplicado da adubação de semeadura, o que reduz a formação do sistema radicular (TEIXEIRA et al., 2015). Por isso, quando o calcário for aplicado na entressafra, em solos ácidos, recomenda-se que haja um intervalo entre as primeiras chuvas e a semeadura, pois a água é importante para a reação do calcário no solo.

Tabela 1. Caracterização química do solo e massa de forragem de capim Ipyporã implantado 45 dias após a calagem em solo submetido a diferentes números de irrigações.

Table 1. Soil chemical characterization and forage mass of Ipyporã grass implanted 45 days after liming in soil subjected to different irrigations numbers.

\begin{tabular}{lccccccc}
\hline \multirow{2}{*}{ Variáveis } & \multicolumn{3}{c}{ Número de irrigações* } & \multicolumn{2}{c}{ P-valor } & CV \\
\cline { 2 - 8 } & 1 & 2 & 3 & 9 & $\mathrm{~L}$ & $\mathrm{Q}$ & $\%$ \\
\hline pH do solo $\left(\mathrm{CaCl}_{2}\right)$ & 5,13 & 5,16 & 5,03 & 5,16 & 0,78 & 0,53 & 1,48 \\
Saturação de bases $(\%)$ & 49 & 47 & 45 & 48 & 0,27 & 0,13 & 4,82 \\
Saturação de alumínio $(\%)$ & 0 & 0 & 0 & 0 & 0,99 & 0,99 & $*$ \\
Massa de forragem $\left(\mathrm{g} \mathrm{vaso}^{-1}\right)$ & 2,58 & 2,42 & 2,11 & 2,31 & 0,09 & 0,37 & 15,93 \\
\hline
\end{tabular}

*Cada irrigação elevou a umidade do solo para a capacidade de campo. Adaptado de Melo et al. (2019).

Além disso, para implantação de pastagens, é mencionado que o solo deve conter um teor de cálcio de 1,5

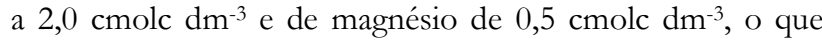
resulta em uma relação $\mathrm{Ca}: \mathrm{Mg}$ de 3 a 4:1 (CANTARUT'TI et al., 1999). Contudo, observando-se a baixa extração destes nutrientes pelas forrageiras (PRIMAVESI et al., 2004a; PRIMAVESI et al., 2006), é possível que teores menores que estes supram a demanda do capim e, diante disso, os níveis descritos por Cantarruti et al. (1999) tem maior importância para a neutralização a acidez do que para o suprimento de cálcio e magnésio. Por exemplo, extrações de cálcio de $40 \mathrm{~kg}$ $\mathrm{ha}^{-1}$ representam teores deste nutriente no solo de $0,1 \mathrm{cmolc}$ $\mathrm{dm}^{-3}$. Para escolha de calcário, diante de escassez de magnésio no solo, deve-se priorizar a aquisição de calcário dolomítico e diante das demais situações deve considerar o critério econômico, principalmente por conta do custo com o transporte do insumo.

Para calagem de manutenção, ou seja, de pasto implantado, recomenda-se aplicar $25 \%$ da quantidade preconizada pelos métodos de recomendação, em virtude da baixa mobilidade do calcário no perfil do solo (CANTARUTTI et al. 1999; DA COSTA; CRUSCIOL, 2016). Todavia, aplicações de até $8 \mathrm{t} \mathrm{ha}^{-1} \mathrm{em}$ cobertura não resultaram em redução na produtividade de braquiárias
(PRIMAVESI et al., 2004a; CARDOSO et al., 2016). Estas elevadas doses de calcário não prejudicam a massa de forragem quando aplicadas em pastos implantados por dois motivos: primeiro, o excesso de calcário reduz disponibilidade de fósforo por precipitação, e este nutriente tem baixa concentração em lâminas foliares e, por isso, é pouco requerido na manutenção do pasto. Em elevado $\mathrm{pH}$ ocorre redução na disponibilidade de micronutrientes catiônicos, que são pouco extraídos por braquiárias (PRIMAVESI et al., 2004a; MORTON, 2018).

Sabe-se que a calagem de manutenção não resulta $\mathrm{em}$ aumento instantâneo na massa de forragem, pois observa-se impacto na produtividade a partir do quarto ano após a aplicação do calcário (PRIMAVESI et al., 2004b; PEREIRA et al., 2018). Entretanto, estes resultados tardios ocorrem diante de sistemas que utilizam baixas quantidades de fertilizantes ou em solos que já estão com a saturação de bases exigida pela cultura (PRIMAVESI et al., 2004b; PEREIRA et al., 2018). Por isso, diante de sistemas mais intensivos, com maior uso de fertilizantes, a calagem proporciona resultados mais imediatos, pois esta prática aumenta a CTC do solo, o que diminui os riscos de fixação de fósforo e de lixiviação de nitrogênio e potássio. 
Para recomendação da calagem é primordial realizar a análise de solo, a partir de uma adequada amostragem de solo, pois somente dessa forma é possível avaliar a necessidade de calcário e do tipo de calcário demandado (calcítico ou dolomítico) de forma criteriosa. Além disso, após a aplicação de calcário, é necessário realizar anualmente análise de solo para que seja possível identificar o momento para a reaplicação desse importante insumo que influencia na disponibilidade de todos os nutrientes.

\subsection{Adubação fosfatada}

$\mathrm{Na}$ adubação de implantação de pastagens, a necessidade de fósforo é elevada principalmente em solos com baixo teor deste nutriente. Nesta condição, para implantar forrageiras de alta exigência em nutrientes (Panicum, Pennisetum e Cynodon), as doses de fósforo requeridas podem atingir $200 \mathrm{~kg} \mathrm{P}_{2} \mathrm{O}_{5} \mathrm{ha}^{-1}$ em solos com teores de fósforo muito baixos (CANTARUTTI et al., 1999; HEINRICHS et al., 2016). Mesmo com baixas concentrações nas lâminas foliares e colmo, o fósforo é muito importante para o estabelecimento do sistema radicular, o que acarreta alteração na massa de forragem (Figura 1), o tornando o nutriente mais limitante para a formação de pastagens em solos de baixa fertilidade (PRIMAVESI et al., 2004a; PRIMAVESI et al., 2006; HALING et al., 2016).

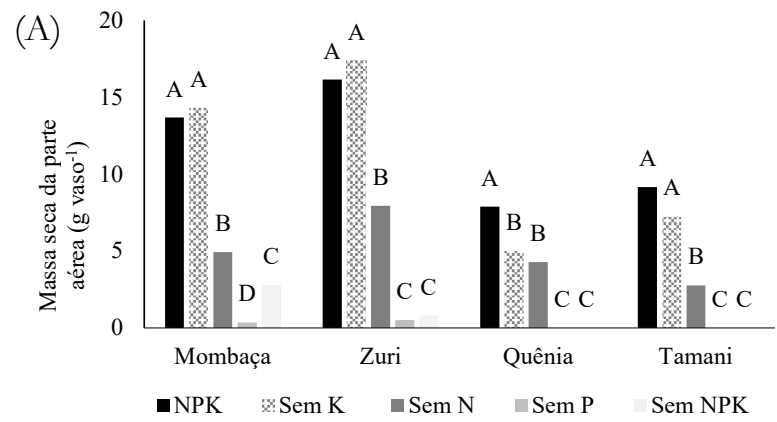

(B)

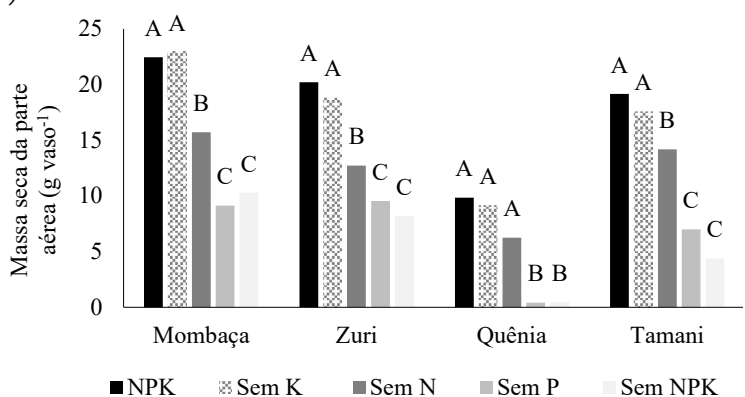

Figura 1. Primeiro crescimento de capins do gênero Panicum implantados com a omissão de macronutrientes primários (A) e primeira rebrota destes capins após a realização de uma adubação de manutenção com NPK (B).

Figure 1. First growth of guineagrass cultivars implanted with omission of primary macronutrients (A) and first regrowth of these grasses after maintenance fertilizer with NPK (B).

$\mathrm{Na}$ ausência de fósforo, observa-se que capins do gênero Panicum implantados em Latossolo com baixo teor de fósforo reduzem a produção em torno de $98,5 \%$ (Figura 1A), o que demonstra o impacto desse nutriente na formação de pastos. Em solos com baixo teor de fósforo, quando não se realiza a adubação de implantação com fósforo, e realiza-se a adubação de manutenção com todos os nutrientes (nitrogênio, fósforo e potássio) para restabelecer a produção, percebe-se que mesmo assim, ocorre redução na massa de forragem da primeira rebrota (Figura 1B), comparativamente ao capim que foi adubado adequadamente com NPK na formação e na manutenção. Dessa forma, quando há negligência no uso de fósforo na formação do pasto, existe impacto na produção mesmo com adubações posteriores, o que demonstra que cada capim terá o período de recuperação e assim, restrição na massa de forragem.

Além da importância do fósforo na formação do pasto, existe uma relação intrínseca entre a adubação fosfatada e a calagem. A calagem minimiza a fixação de fósforo e impede a precipitação com o alumínio e micronutrientes catiônicos (Fe, $\mathrm{Mn}, \mathrm{Zn}$ e $\mathrm{Cu}$ ), pois aumenta a capacidade de troca catiônica e indisponibiliza o alumínio tóxico, o que aumenta a eficiência da adubação fosfatada (MORTON, 2018; MIOTTO et al., 2019).

Dessa forma, observa-se maior demanda de fósforo quando não se aplica calcário para estabelecimento de capins em solos ácidos (Figura 2). Na perspectiva econômica, o menor custo é observado quando se adota a calagem e reduz a quantidade de fertilizante fosfatado, pois o calcário é um insumo menos oneroso (Figura 2). Desta forma, foi observado esta resposta na implantação de Andropogon gayanus, que é uma gramínea de baixa exigência em fertilidade do solo (Figura 2) e maiores restrições poderão ser observadas em gramíneas de média a alta exigência em fertilidade, o que reafirma a demanda de conjugar a calagem e a adubação fosfatada.

Como o fósforo representa a maior parcela no custo da adubação de implantação de pastos em solos de baixa fertilidade, o uso de fosfato natural é uma forma de reduzir o custo, pois é um fertilizante mais barato por quilo de $\mathrm{P}_{2} \mathrm{O}_{5}$, além de reduzir a fixação e precipitação de fósforo. Em contrapartida, é um fertilizante com baixa disponibilidade inicial de fósforo, com solubilização gradativa por meio da acidez. Diante disso, em solos com baixo teor de fósforo, o uso desse fertilizante pode limitar o estabelecimento do capim. Para uso em solos sem demanda de calcário ou com acidez corrigida, o sulfato de amônio pode potencializar a solubilização desse fertilizante (CABRAL et al., 2018). Porém, deve-se fazer análise econômica, pois o fosfato reduz o custo da adubação fosfatada e o sulfato de amônio aumenta o custo da adubação nitrogenada

Além disso, em casos de uso prévio de fosfato natural (ou reativo) na área, deve-se evitar o uso métodos que utilizam extratores ácidos para estimar os teores de fósforo (Mehlich1; Mehlich-3), pois os resultados superestimarão o fósforo disponível para forrageiras. Neste caso, o uso de resina aniônica para estimar a disponibilidade de fósforo é mais adequado (FREITAS et al., 2013).

Enquanto a adubação fosfatada é muito importante na implantação de pastagens, na fase de manutenção são requeridas baixas quantidades de fósforo. Por meio de equações (SOUSA et al., 2007) verifica-se que as demandas de fósforo $\left(\mathrm{P}_{2} \mathrm{O}_{5}\right)$ variam de 15 a $70 \mathrm{~kg} \mathrm{ha}^{-1}$ ou 0 a $60 \mathrm{~kg} \mathrm{ha}^{-1}$ conforme tabela de recomendação (CANTARUTTI et al., 1999). Para capins com produção anual de $20 \mathrm{t} \mathrm{MS} \mathrm{ha}^{-1}$, existem recomendações de 40 a $50 \mathrm{~kg} \mathrm{P}_{2} \mathrm{O}_{5} \mathrm{ha}^{-1}$, enquanto pastagens extensivas com taxa de lotação menor que $1 \mathrm{UA}$ $\mathrm{ha}^{-1}$, recomendam-se aplicar $20 \mathrm{~kg} \mathrm{P}_{2} \mathrm{O}_{5} \mathrm{ha}^{-1}$, a cada dois anos (SOARES et al., 2001). 
Desse modo, em manutenção de pastagens, a maior relevância do fósforo ocorre diante de recuperação de pastos degradados, visto que quando a forragem é submetida a contínua restrição fotossintética, observa-se consumo de carboidratos de reserva das raízes, o que pode tornar o sistema radicular superficial (SOARES FILHO et al., 2013). Por isso, nesta situação, o fósforo favorecerá o desenvolvimento radicular, para que posteriormente a forrageira seja capaz de absorver os demais nutrientes, o que minimizará perdas excessivas de nitrogênio e potássio por lixiviação e explicar o efeito sinérgico entre a adubação fosfatada e nitrogenada (BÉLANGER et al., 2016).

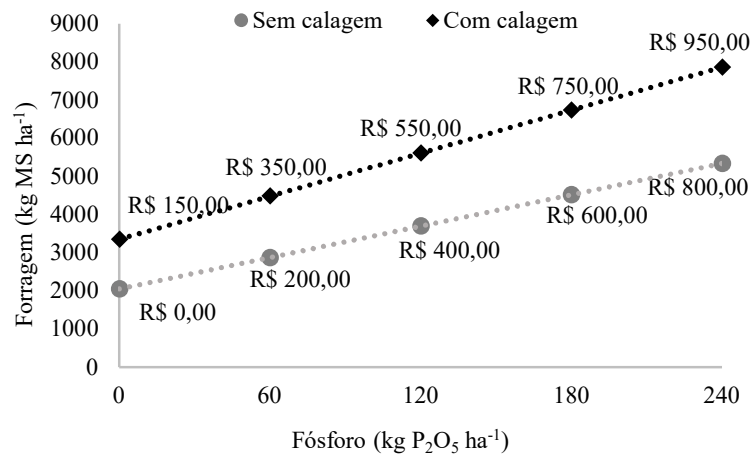

Figura 2. Massa de forragem e custo de corretivos e fertilizantes para estabelecimento Andropogon gayanus em solo de Cerrado. Dose de calcário: $1 \mathrm{Mg}$ ha $^{-1}$; Calcário: $\mathrm{R} \$ 150$ tonelada $^{-1}$; Fosfato monoamônico (MAP): US $\$ 420$ tonelada $^{-1}$. Fonte: Adaptado de Couto et al. (1988) citado por Sousa et al. (2007).

Figure 2. Forage mass and correctives and fertilizers costs for establishment Andropogon gayanus in Cerrado soil. Limestone dose: 1 $\mathrm{Mg}$ ha $^{-1}$; Limestone: $\mathrm{R} \$ 150$ metric ton ${ }^{-1}$; Monoammonium phosphate (MAP): $\$ 420$ metric ton ${ }^{-1}$. Source: Adapted from Couto et al. (1988) cited by Sousa et al. (2007).

\subsection{Adubação nitrogenada}

O nitrogênio é o nutriente mais estudado na adubação de capins por ser um dos nutrientes mais extraído, além de aumentar a massa de forragem e alterar a morfogênese (PRIMAVESI et al., 2006; BACKES et al., 2018). Este nutriente aumenta a emissão de folhas, a densidade de perfilhos, reduz o filocrono e acelera a senescência da planta forrageira quando não colhida no momento adequado (PACIULLO et al., 2016; MARTUSCELLO et al., 2019). Por isso, a adubação nitrogenada deve estar sempre associada ao manejo do pastejo para evitar perdas de forragem.

$\mathrm{Na}$ implantação de capins, a quantidade de nitrogênio suprida por meio de adubação é pequena, pois a mineralização da matéria orgânica supre parte do nitrogênio requerido. Por isso, alguns métodos consideram o teor de matéria orgânica e a textura para a adubação nitrogenada de implantação.

Para solos arenosos ou com teor de matéria orgânica menor que $16 \mathrm{~g} \mathrm{dm}^{-3}$ recomenda-se a aplicação de 60 a $65 \mathrm{~kg}$ $\mathrm{ha}^{-1}$ de $\mathrm{N}$, sendo que 25 a $30 \mathrm{~kg} \mathrm{ha}^{-1}$ deve ser aplicado de $5 \mathrm{a}$ 6 semanas após a semeadura e o restante após o primeiro pastejo, para estimular o perfilhamento. Para solos de textura média a argilosa e com teores de matéria orgânica maior que $16 \mathrm{~g} \mathrm{dm}^{-3}$, recomenda-se a aplicação de 30 a $35 \mathrm{~kg} \mathrm{ha}^{-1}$ de nitrogênio somente após o primeiro pastejo (MARTHA JUNIOR et al., 2007).

Para capins do gênero Panicum, a omissão de nitrogênio reduz a massa de forragem no primeiro crescimento do capim (Figura 1), mesmo em solos com teor de matéria orgânica maior que $16 \mathrm{~g} \mathrm{dm}^{-3}$. Por isso, conclui-se que matéria orgânica pode não suprir a necessidade de nitrogênio de capins mais produtivos, o que requer a aplicação de nitrogênio antes do primeiro pastejo. Entretanto, a omissão de nitrogênio na formação de pasto é menos prejudicial que a omissão de fósforo, pois as plantas antecessoras que são mineralizadas garantem maior ciclagem de nitrogênio no sistema, comparativamente ao fósforo (GALINDO et al., 2018).

Todavia, em casos em que o pasto será implantado em áreas onde a cultura antecessora tenha baixo teor de nitrogênio, como capineiras de cana-de-açúcar, a adubação nitrogenada torna-se relevante, pois a elevada relação $\mathrm{C} / \mathrm{N}$ pode permitir que ocorra imobilização temporária do nitrogênio pelos microrganismos (RAMOS et al., 2016).

Outra recomendação de adubação de estabelecimento preconiza que a adubação nitrogenada seja variável conforme o método de pastejo (lotação contínua e rotativa) e a gramínea utilizada. Assim, as doses variam de 0 a $150 \mathrm{~kg} \mathrm{ha}$ 1, cuja ausência de adubação é recomendada para capins de baixa produção em sistema extensivo (sem ajuste da taxa de lotação) e as maiores doses recomendadas para capins (Brachiaria brizantha, Panicum maximum, Pennisetum purpureum e Cynodon sp.) em lotação rotativa (CANTARUTTI et al., 1999).

Quanto a adubação nitrogenada de manutenção de pastagens, existem diversas recomendações, que variam conforme o planejamento da propriedade rural e do método de pastejo. Uma delas baseia-se no manejo da pastagem e recomenda-se 200, 100 e $50 \mathrm{~kg} \mathrm{~N} \mathrm{ha}^{-1}$ para sistemas em lotação rotativa, lotação contínua com ajuste da taxa de lotação e lotação contínua sem ajuste da taxa de lotação, respectivamente (CANTARUT'TI et al., 1999).

Em lotação contínua em fase de intensificação, recomenda-se o parcelamento da adubação em três vezes, mas em sistemas menos intensificados pode-se reduzir o número de aplicações para duas vezes, sendo uma no início das águas para estimular perfilhamento e restabelecimento das reservas orgânicas e outra no terço final das águas, para que seja possível iniciar o período seco com considerável massa de forragem. Em lotação rotativa, a adubação com nitrogênio pode ser parcelada a cada saída dos animais (CANTARUTTI et al., 1999).

Outro método de recomendação de adubação considera o tamanho do rebanho e o período de pastejo. Por meio de estimativa do consumo dos animais é possível obter a quantidade total demandada de matéria seca de pasto e, a partir disso, admitir a quantidade de nitrogênio requerida (Tabela 2). Após conhecer a dose, deve-se considerar a quantidade máxima de nitrogênio que deve ser utilizada por aplicação. No caso do capim braquiarão (B. brizantha $\mathrm{cv}$. Marandu), a gramínea mais expressiva no Brasil, recomendase que a máxima dose de nitrogênio por aplicação seja de 50 $\mathrm{kg} \mathrm{ha}^{-1} \mathrm{e}$, em casos de início de degradação, pode-se utilizar até $75 \mathrm{~kg} \mathrm{ha}^{-1}$ para acelerar a recuperação (SALES et al., 2020).

Além da dose de nitrogênio, principalmente em sistema em lotação rotativa, tem-se a dúvida de quantos dias após a desfolha deve-se realizar a adubação de cobertura. Para o capim Piatã recomenda-se que a adubação seja feita o mais próximo da desfolha, ou seja, logo após a saída dos animais do piquete, pois em adubação tardia evidencia-se redução na massa de forragem (FARIA et al., 2019). Contudo, para os 
capins Marandu, Xaraés, BRS Quênia, BRS Zuri, Massai existe pouco efeito da época de adubação sobre a massa de forragem, o que garante mais flexibilidade no manejo da adubação (PEREIRA et al., 2012; MARQUES et al., 2016; GOMIDE et al., 2019; FARIA et al., 2019). É provável que a maior flexibilidade quanto ao momento de realizar a adubação nitrogenada esteja associada ao baixo teor de reservas nitrogenadas na base do colmo e raízes das gramíneas forrageiras.

Tabela 2. Adubação de manutenção baseada na massa de forragem produzida a cada 100 quilos de nitrogênio utilizado na adubação.

Table 2. Maintenance fertilization based on forage mass in every 100 kilos of nitrogen used in fertilization.

\begin{tabular}{|c|c|c|}
\hline Capim & $\mathrm{kg}$ MS $100 \mathrm{~kg} \mathrm{~N}^{-1}$ & Referências \\
\hline Marandu & 1200 a 1700 & $\begin{array}{l}\text { Primavesi et al. (2006) e } \\
\text { Sales et al. (2020) }\end{array}$ \\
\hline Xaraés & 1700 & Campos et al. (2016) \\
\hline Coastcross & 2100 & Primavesi et al. (2004a) \\
\hline Mombaça & 3000 a 3500 & Mello et al. (2008) \\
\hline
\end{tabular}

Quando se utiliza ureia na adubação de pastagens, devese tomar cuidado quanto ao momento de aplicação. Temperaturas elevadas aumentam as perdas de nitrogênio por volatilização, bem como chuvas antes da adubação, pois à medida que aumenta a umidade do solo, ocorre aceleração na hidrólise da ureia (CASCALDI et al., 2020). Logo, a combinação do elevado teor de umidade do solo, a alta temperatura e da ausência de chuva nos primeiros dias após adubação podem resultar em perda de nitrogênio por volatilização em até $40 \%$. Por isso, recomenda-se a aplicação da ureia quando houver previsão de chuva, uma vez que o pico de volatilização de nitrogênio ocorre de 3 a 6 dias após a adubação (TASCA et al., 2011).

Para a maximização da eficiência da ureia na adubação das pastagens, pode-se utilizá-la associada aos inibidores de urease, como o NBPT ((N-(n-butil) tiofosfórico triamida) (TASCA et al., 2011). Entretanto, deve-se ter atenção à data da validade, visto que de 60 a 90 dias após a fabricação ocorre queda na eficácia da ureia com NBPT, assemelhando-se a ureia convencional. Os demais métodos que inibem a volatilização de amônia ou liberação de ureia controlada possuem diversos resultados na literatura, o que impede uma conclusão concisa sobre a eficácia destes produtos (CHAGAS et al., 2017).

Nos últimos anos foram lançados diversos capins e, diante disso, existe dificuldade em identificar a necessidade nutricional para realizar uma adubação adequada. Por meio da identificação da espécie é possível ter uma noção sobre a demanda nutricional da gramínea, contudo, programas de melhoramento de forrageiras podem utilizar mais de uma espécie para a formação dos híbridos, o que dificulta o reconhecimento da exigência nutricional.

Diante desta problemática, enquanto não houver vários estudos sobre a adubação dos novos capins, pode-se realizar experimentos em casa de vegetação e utilizar o teste de identidade de modelos para comparar a resposta das novas gramíneas aos capins mais consagrados na literatura e presentes em tabelas de recomendação de adubação. Por meio desta metodologia, identificou que o capim BRS Ipyporã tem média exigência nitrogênio e que o capim Convert HD 364(Mulato II - B. ruziziensis $\times$ B. brizantha $\times B$. decumbens ) assemelha-se a exigência em nitrogênio do capim Braquiarão (B. brizantha cv. Marandu) (CABRAL et al., 2020).
As leguminosas, por meio da simbiose com bactérias diazotróficas, são capazes de fixar nitrogênio atmosférico. Assim, quando consorciadas com gramíneas forrageiras, as leguminosas proporcionam redução na demanda de fertilizantes nitrogenados, pois após mineralização da fitomassa, o nitrogênio pode ser absorvido pela cultura em consórcio. O consórcio de amendoim forrageiro com capim Marandu proporcionou resultados melhores que pastos de capim Marandu adubado exclusivamente com $120 \mathrm{~kg} \mathrm{ha}^{-1}$ (PEREIRA et al., 2019). A dificuldade na adoção de consórcios é o manejo do pastejo, pois são plantas com diferente potencial de rebrota.

\subsection{Adubação potássica}

O potássio é um nutriente pouco estudado em gramíneas forrageiras, comparativamente ao nitrogênio. Entretanto, sabe-se que quando se aumenta o suprimento de nitrogênio na adubação, ocorre incremento na extração de potássio (PRIMAVESI et al., 2004a; PRIMAVESI et al., 2006). Diante disso, quando há baixo teor de potássio no solo, a adubação potássica, pode ser realizada na semeadura, junto com o fósforo, ou em cobertura, junto com a adubação nitrogenada (VILELA et al., 2007b).

A adubação potássica torna-se desnecessária na implantação de pasto quando os teores desse nutriente no solo são maiores que 50 e $70 \mathrm{mg} \mathrm{dm} 3$ (VILELA et al., 2007b; CANTARUTTI et al., 1999). Contudo, pode existir exceções, como o capim BRS Quênia (Figura 1), que restringiu a massa de forragem quando implantado na ausência de potássio e em solo com teor de potássio maior que $50 \mathrm{mg} \mathrm{dm}^{-3}$.

$\mathrm{Na}$ adubação de manutenção, quando o solo tiver um teor de potássio que demande baixas doses (menores que $40 \mathrm{~kg}$ $\mathrm{K}_{2} \mathrm{O}$ ha $^{-1}$ ), deve-se realizar uma única aplicação no início das águas (CANTARUT'TI et al., 1999). E outros casos, deve-se parcela junto com o nitrogênio.

Como ocorre proporcionalidade entre a extração de nitrogênio e potássio pelas gramíneas forrageiras (PRIMAVESI et al., 2004a; PRIMAVESI et al., 2006), temse estudado uma relação entre estes dois nutrientes. Para capins do gênero Panicum, tem-se observado que a dose de potássio aplicada seja a metade da dose de nitrogênio, o que confere uma relação nitrogênio:potássio de 2:1, similar a relação obtida para o Pennisetum (NOVO et al., 2016; BARBEDO et al., 2020). Porém, devem ser realizados trabalhos com gramíneas do gênero Brachiaria, pois é o gênero predominante na pecuária de corte do Brasil e, além disso, os resultados são escassos.

Por fim, como comumente as propriedades iniciam a adubação de pastagens com o uso de fertilizante nitrogenado, e como a extração de potássio é proporcional à extração de nitrogênio, a inserção do potássio na adubação de pastagens aumenta a massa de forragem e os ciclos de desfolha (BACKES et al., 2018; SANTOS et al., 2019; JUNGERS et al., 2019). Contudo, estudos de viabilidade econômica da adubação potássica devem ser realizados, principalmente em sistemas em lotação rotativa.

\subsection{Adubação com enxofre e demais nutrientes}

Para correção do alumínio em profundidade, em camadas abaixo de $20 \mathrm{~cm}$, o gesso pode contribuir de modo efetivo. $\mathrm{O}$ gesso é um condicionador de solo que neutraliza o alumínio e lixivia bases em profundidade, o que permite aprofundamento do sistema radicular. 
Uma vantagem esperada no uso de gesso nas pastagens da pecuária de corte é o adiamento dos efeitos do período seco ou estiagem, em virtude do sistema radicular mais profundo (SOUSA et al., 2005). A maior limitação para o uso de gesso é a aquisição do insumo, pois a produção está vinculada a indústria de fertilizantes fosfatados, que não estão regularmente distribuídas no Brasil. Por exemplo, em Mato Grosso, que é o estado com maior rebanho bovino, não existe indústria de gesso, o que demanda a aquisição mais próxima seja feita de Goiás.

Além de ser um condicionador de solo, o gesso supre enxofre, que é um importante nutriente para síntese de aminoácidos sulfurosos. Diante da indisponibilidade de gesso, a adubação com enxofre pode ser realizada na semeadura vinculada com a fosfatada (superfosfato simples), ou em cobertura associada com a nitrogenada (sulfato de amônio), sendo desnecessária a aplicação nos dois momentos, principalmente porque estes dois fertilizantes aumentam o custo de produção (SILVA et al., 2019). Existem poucos trabalhos sobre o efeito do enxofre na implantação da forrageira, de modo que existe recomendação média de enxofre de $30 \mathrm{~kg} \mathrm{ha}^{-1}$ ou relação nitrogênio:enxofre de 10:1 (CANTARUTTI et al., 1999; VILELA et al., 2007a).

Quanto à adubação de manutenção com enxofre os resultados são diversos, pois alguns autores que não verificaram efeito pronunciado do enxofre sobre a massa seca da rebrota de forrageiras, o que pode ser explicado pelo suprimento por meio da mineralização da matéria-orgânica diante da baixa extração de enxofre (BATISTA; MONTEIRO, 2006; BONFIM-SILVA et al., 2007). Em contrapartida, existem autores que evidenciaram efeito da adubação sulfurosa em forrageiras (SCHIMIDT; MONTEIRO, 2015; SANTOS et al., 2019). A maior parte dos trabalhos foram realizados com gramíneas do gênero Brachiaria e por isso, é uma lacuna científica identificar a exigência em enxofre de capins mais produtivos. Além disso, os micronutrientes são pouco estudados para pastagens, contudo, sabe-se da essencialidade desses nutrientes e que em solos de Cerrado, a escassez de zinco ou molibdênio pode ser uma limitação ou em solos com elevado pH é comum evidenciar a deficiência de micronutrientes catiônicos.

\section{CONSIDERAÇÕES FINAIS}

$\mathrm{Na}$ implantação de pastagens, em solos de baixa fertilidade, deve-se considerar a seguinte demanda preferencial de nutrientes: fósforo, nitrogênio, potássio e micronutrientes. Em casos de solos ácidos, a calagem é imprescindível para evitar perdas do fósforo por fixação e precipitação. No estabelecimento do pasto, o insumo de maior custo é o fertilizante fosfatado, que pode representar até $80 \%$ do custo dos fertilizantes, principalmente em solos argilosos. Comparando-se dois solos de baixo teor em nutrientes, um solo arenoso terá o custo $40 \%$ menor que um solo argiloso, principalmente pela menor demanda em fósforo, contudo, haverá maior demanda em nitrogênio, pelo menor teor em matéria-orgânica.

Enquanto o principal componente de gasto na formação de pasto é o fósforo, para manutenção o nitrogênio é o primeiro limitante, visto que a sequência de prioridade é: nitrogênio, potássio, fósforo e micronutrientes. Casos esporádicos podem antecipar a demanda de micronutrientes, visto que são nutrientes demandados em menor quantidade. Por isso, o custo da adubação de manutenção depende do grau de investimento da propriedade rural, de modo que a adubação nitrogenada vai representar a maior parte do custo (até $80 \%$ ).

Comumente os pecuaristas fazem a aquisição de "varredura", que corresponde as sobras provenientes das indústrias e armazenagem dos fertilizantes. De modo geral, as varreduras têm menor custo por tonelada de produto, mas nem sempre por tonelada de nutriente, o que pode tornar este produto pouco viável. Por isso, para uso adequado de varreduras, deve-se fazer análise dos teores de nutrientes.

Por fim, o uso viável da adubação deve ser precedido de importantes etapa: manejo do pastejo (altura do dossel forrageiro), redução do tamanho dos pastos, gestão de aquisição dos animais e acompanhamento de desempenho animal. A partir disso, será possível estimar a demanda de forragem, para então realizar o suprimento dos nutrientes demandados, por meio de análise periódica de solo. Após o adequado manejo do pastejo e adubação racional, poderá então ser dado o próximo passo a intensificação, que é a suplementação e a irrigação.

\section{REFERÊNCIAS}

ABIEC_Associcação Brasileira das Indústrias Exportadoras de Carnes. Beef Report: Perfil da pecuária no Brasil. $2020 . \quad$ Disponível em: http://abiec.com.br/publicacoes/beef-report-2020/. Acesso em: 24 fev 2021.

ALMEIDA, T. F.; CARVALHO, J. K.; REID, E.; MARTINS, A. P.; BISSANI, C. A.; BORTOLUZZI, E. C.; BRUNETTO, G.; ANGHINONI, I.; CARVALHO, P. C. F.; TIECHER, T. Forms and balance of soil potassium from a long-term integrated crop-livestock system in a subtropical Oxisol. Soil and Tillage Research, v. 207, p. 104864, 2021. DOI: https://doi.org/10.1016/j.still.2020.104864.

BACKES, C. C.; SANTOS, A. J. M.; BESSA, S. V.; RIBON, A. A.; TEODORO, A. G.; RODRIGUES, L. M.; TOMAZELO, D. A.; LEITE, L. L. F. Taxa de cobertura verde e exportação de macronutrientes pelo capim Marandu em função da aplicação de gesso. Archivos de Zootecnia, v. 67, n. 258, p. 234-242, 2018. DOI: https://doi.org/10.21071/az.v67i258.3659.

BARBEDO, P. F.; ASSUNÇÃO, M. L. P.; ALVES, R. V.; LIMA, M. S.; BORGHI, N. F.; KNOBLAUCH, A. S. S.; SILVA, J. O. Produção de diferentes cultivares de panicum maximum e urocbloa brizantha adubados com nitrogênio e potássio. Brazilian Journal of Development, v. 6, n. 8, p. 60163-60169, 2020. DOI: https://doi.org/10.34117/bjdv6n8-435.

BATISTA, K.; MONTEIRO, F. A. Respostas morfológicas e produtivas do capim-marandu adubado com doses combinadas de nitrogênio e enxofre. Revista Brasileira de Zootecnia, v. 35, n. 4, p. 1281-1288, 2006. DOI: https://doi.org/10.1590/S1516-35982006000500005.

BÉLANGER, G.; ZIADI, N.; LAJEUNESSE, J.; JOUANY, C.; VIRKAJARVI, P.; SINAJ, S.; NYIRANEZA, J. Shoot growth and phosphorus-nitrogen relationship of grassland swards in response to mineral phosphorus fertilization. Field Crops Research, v. 204, p. 31-41, 2017. DOI: https://doi.org/10.1016/j.fcr.2016.12.006.

BONFIM-SILVA, E. M.; MONTEIRO, F. A.; SILVA, T. J. A. Nitrogênio e enxofre na produção e no uso de água pelo capim-braquiária em degradação. Revista 
Brasileira de Ciência do Solo, v. 31, p. 309-317, 2007. https://doi.org/10.1590/S0100-06832007000200013.

CABRAL, C. E. A.; CABRAL, L. S.; BONFIM-SILVA, E. M.; CARVALHO, K. S.; ABREU, J. G.; CABRAL, C. H. A. Reactive natural phosphate and nitrogen fertilizersin Marandu grass fertilization. Comunicata Scientiae, Bom Jesus, v. 9, n. 4, p. 729-736, 2018. DOI: https://doi.org/10.14295/cs.v9i4.1170.

CABRAL, C. E. A.; CABRAL, C. H. A.; TESK, C. R. M.; MOTA, L. G.; GROTO, G. C.; MOTTA, L. J. M.; LOURENÇO, P. E. C.; MOTTA, A. M.; BARROS, L. V.; SILVA, F.G.; ABREU, J.G.; SANTOS, A.R.M. Nitrogen requirement of brachiaria hybrid cv. Ipyporã. Boletim de Indústria Animal, v. 77, p. 1-10, 2020 DOI: https://doi.org/10.17523/bia.2020.v77.e1467.

CAMPOS, F. P.; NICÁCIO, D. R. O.; SARMENTO, P.; CRUZ, M. C. P.; SANTOS, T. M.; FARIA, A. F. G.; FERREIRA, M. E.; CONCEIÇÃO, M. R. G.; LIMA, C. G. Chemical composition and in vitro ruminal digestibility of hand-plucked samples of Xaraes palisade grass fertilized with incremental levels of nitrogen. Animal Feed Science and Technology, v. 215, n. 1, p. 1-12, 2016.2 DOI: https://doi.org/10.1016/j.anifeedsci.2015.12.013.

CANTARUTTI, R. B.; MARTINS, C. E.; CARVALHO, M. M.; FONSECA, D. M.; ARRUDA, M. L.; VILELA, H.; OLIVEIRA, F. T. T. Pastagens. In: RIBEIRO, A. C.; GUIMARÃES, P. T. G.; ALVAZEZ V. V. H. (Eds.) Recomendações para uso de corretivos e fertilizantes em Minas Gerais. Viçosa, 1999. p. 332341

CARDOSO, S.; VOLPE, E.; MACEDO, M. C. M. Effect of nitrogen and lime on Massai grass subjected to intensive cutting. Pesquisa Agropecuária Tropical, v. 46, n. 1, p. 19-27, 2016. DOI: http://dx.doi.org/10.1590/1983$40632016 v 4638132$.

CASCALDI, A. M. S.; FARIA, R. T.; PALARETTI, L. F.; SANTOS, M. G.; FISCHER FILHO, J. A.; CAZETTA, J. O. Volatilização de amônia proveniente de ureia protegida em braquiária irrigada. Irriga, Botucatu, v. 25, n. $1, \quad$ p. $58-68, \quad 2020$. DOI: https://doi.org/10.15809/irriga.2020v25n1p58-68.

CHAGAS, P. H. M.; GOUVEIA, G. C. C.; COSTA, G. G. S.; BARBOSA, W. F. S.; ALVES, A. C. Volatilização de amônia em pastagem adubada com fontes nitrogenadas. Revista de Agricultura Neotropical, v. 4, n. 2, p. 76 80, 2017. https://doi.org/10.32404/rean.v4i2.1301.

DA COSTA, C. H. M.; CRUSCIOL, C. A. C. Long-term effects of lime and phosphogypsum application on tropical no-till soybean-oat-sorghum rotation and soil chemical properties. European Journal of Agronomy, v. 74, p. 119-132, 2016. DOI: https://doi.org/10.1016/j.eja.2015.12.001.

FARIA, D. A.; AVELINO, A. C. D.; CABRAL, C. E. A.; ABREU, J. G.; BARROS, L. V.; CABRAL, C. H. A.; DANTAS, V. G. V.; GUARNIERI, S. F.; BEHLING NETO, A.; ASSIS, L. M. B. Investigating the optimal day for nitrogen fertilization on Piatã palisadegrass and Quênia guineagrass after defoliation. Journal of Experimental Agriculture International, v. 34, n. 6, p. 1-11, 2019.

DOI: https://doi.org/10.9734/jeai/2019/v34i630192.

FREITAS, I. F.; NOVAIS, R. F.; VILLANI, E. M. A.; NOVAIS, S. V. Phosphorus extracted by ion exchange resins and Mehlich-1 from Oxisols (Latosols) treated with different phosphorus rates and sources for varied soilsource contact period. Revista Brasileira de Ciência do Solo, v. 37, n. 3, p. 667-677, 2013. DOI: http://dx.doi.org/10.1590/S0100-06832013000300013.

GALINDO, F. S.; BUZETTI, S.; TEIXEIRA FILHO, M. C. M.; DUPAS, E.; LUDKIEWICZ, M. G. Z. Acúmulo de matéria seca e nutrientes no capim-mombaça em função do manejo da adubação nitrogenada. Revista de Agricultura Neotropical, v. 5, n. 3, p. 1-9, 2018. DOI: https://doi.org/10.32404/rean.v5i3.2132.

GOMIDE, C. A. M.; PACCIULO, D. S. C.; MORENZ, M. J. F.; COSTA, I. A.; LANZONI, C. L. Productive and morphophysiological responses of Panicum maximum Jacq. cv. BRS Zuri to timing and doses of nitrogen application and defoliation intensity. Grassland Science, v. 65 , n. 8 , p. 93-100, 2019. DOI: https://doi.org/10.1111/grs.12226.

HALING, R. E.; YANG, Z.; SHADWELL, N.; CULVERNOR, R. A.; STEFANSKI, A.; RYAN, M. H.; SANDRAL, G. A.; KIDD, D. R.; LAMBERS, H.; SIMPSON, R. J. Growth and root dry matter allocation by pasture legumes and a grass with contrasting external critical phosphorus requirements. Plant and Soil, v. 407, n. $1, \quad$ p. 67-79, 2016. DOI: https://doi.org/10.1007/s11104-016-2808-2.

HEINRICHS, R.; MONREAL, C. M.; SANTOS, E. T.; SOARES FILHO, C. V.; REBONATTI, M. D.; TEIXEIRA, N. M.; MOREIRA, A. Phosphorus Sources and Rates Associated with Nitrogen Fertilization in Mombasa Grass Yield. Communications in Soil Science and Plant Analysis, v. 47, p. 657-669, 2016. http:/ /dx.doi.org/10.1080/00103624.2016.1141923.

JUNGERS, J. M.; KAISER, D. E.; LAMB, J. F. S.; LAMB, J. A.; NOLAND, R. L.; SAMAC, D. A.; WELLS, M. S.; SHEAFFER, C. C. Potassium fertilization affects alfalfa forage yield, nutritive value, root traits, and persistence. Agronomy Journal, v. 111, p. 2843-2852, 2019. DOI: https://doi.org/10.2134/agronj2019.01.0011.

MARTHA JUNIOR, G. B.; VILELA, L.; SOUSA, D. M. G. Adubação nitrogenada. In: MARTHA JUNIOR, G. B.; VILELA, L.; SOUSA, D. M. G. Cerrado: uso eficiente de corretivos e fertilizantes em pastagens. Planaltina: EMBRAPA Cerrados, 2007. p. 145-177. Disponível em: https://www.infoteca.cnptia.embrapa.br/infoteca/bitstr eam/doc/1113533/1/Livro.pdf.

MARQUES, M. F.; ROMUALDO, L. M.; MARTINEZ, J. F.; LIMA, C. G.; LUNARDI, L. J.; LUZ, P. H. C.; HERLING, V. R. Momento de aplicação do nitrogênio e algumas variáveis estruturais e bromatológicas do capimmassai. Arquivo Brasileiro de Medicina Veterinária e Zootecnia, v. 68, n. 3, p. 776-784, 2016. DOI: http:/ /dx.doi.org/10.1590/1678-4162-8500

MARTUSCELLO, J. A.; RIOS, J. F.; FERREIRA, M. R.; ASSIS, J. A.; BRAZ, T. G. S.; CUNHA, D. N. F. V. Produção e morfogênese de capim BRS Tamani sob diferentes doses de nitrogênio e intensidades de desfolhação. Boletim de Indústria Animal, v. 76, n. 1, p. $1-10,2019 . \quad$ DOI: https://doi.org/10.17523/bia.2019.v76.e1441.

MELO, V. B.; MORIGI, R. S.; CABRAL, C. H. A.; CABRAL, C. E. A Quanto de precipitação é necessário, após a calagem, para implantar o capim Ipyporã? In: SIMPÓSIO MATO-GROSSENSE 
BOVINOCULTURA DE CORTE, 5, 2019, Cuiabá Anais... Cuiabá: UFMT, EDUFMT, 2019. Disponível em: https://simbovmt.wixsite.com/simbovmt/anaisc1072

MELLO, S. Q. S.; FRANÇA, A. F. S.; LANNA, A. C.; BERGAMASCHINE, A. F.; KLIMANN, H. J.; RIOS, L. C.; SOARES, T. V. Adubação nitrogenada em capimmombaça: produção, eficiência de conversão e recuperação aparente do nitrogênio. Ciência Animal Brasileira, v. 9, n. 4, p. 935-947, 2008. DOI: https://doi.org/10.5216/cab.v9i4.1231.

MIOTTO, A.; TIECHER, T.; KAMINSKI, J.; BRUNETTO, G.; DE CONTI, L.; TIECHER, T. L.; MARTINS, A. P.; SANTOS, D. R. Soil acidity and aluminum speciation affected by liming in the conversion of a natural pasture from the Brazilian Campos Biome into no-tillage system for grain production. Archives of Agronomy and Soil Science, p. 138-151, 2019. DOI: https://doi.org/10.1080/03650340.2019.1605164

MORTON, J. D. A review of research on the effect of lime on New Zealand soils and pastures. New Zealand Journal of Agricultural Research, v. 61, n. 1, p. 1-13, 2018. https://doi.org/10.1080/00288233.2018.1537293.

NOVO, A. A. C.; DAHER, R. F.; GRAVINA, G. A.; COSTA, E. S.; OGLIARI, J.; ARAÚJO, K. C.; MENEZES, B. R. S.; PONCIANO, N. J.; OLIVEIRA, E. S.; SILVA, V. B. Effect of nitrogen and potassium fertilization on morpho-agronomic traits of three elephant grass (Pennisetum purpureum Schum.) genotypes for biomass production. African Journal of Biotechnology, v. 15, n. 43, p. 2411-2423, 2016. DOI: https://doi.org/10.5897/AJB2016.15615.

PACIULLO, D. S.; GOMIDE, C. A. M.; CASTRO, C. R. T.; MAURÍCIO, R. M.; FERNANDES, P. B.; MORENZ, M. J. F. Morphogenesis, biomass and nutritive value of Panicum maximum under different shade levels and fertilizer nitrogen rates. Grass and Forage Science, v. 72, n. 3, p. 590-600, 2016. DOI: https://doi.org/10.1111/gfs.12264.

PEREIRA, L. E. T.; HERLING, V. R.; AVANZI, J. C.; SILVA, S. C. Morphogenetic and structural characteristics of signal grass in response to liming and defoliation severity. Pesquisa Agropecuária Tropical, v. 48 , n. 1 , p. 1-11, 2018. DOI: https://doi.org/10.1590/1983-40632018v4849212.

PEREIRA, R. C.; RIBEIRO, K. G.; ANDRADE, R. D.; SILVA, J. L.; SILVA, E. B.; FONSECA, D. M.; CECON, P. R.; PEREIRA, O. G. Structural and productive characteristics of Marandu and Xaraés grasses fertilized at different times after harvesting. Revista Brasileira de Zootecnia, v. 41, n. 3, p. 557-564, 2012. DOI: http://dx.doi.org/10.1590/S1516-35982012000300012.

PEREIRA, J. M.; REZENDE, C. P.; BORGES, A. M. F.; HOMEM, B. G. C.; CASAGRANDE, D. R.; MACEDO, T. M.; ALVES, B. J. R.; SANT'ANNA, S. A. C.; URQUIAGA, S.; BODDEY, R. M. Production of beef cattle grazing on Brachiaria brizantha (Marandu grass) Arachis pintoi (forage peanut cv. Belomonte) mixtures exceeded that on grass monocultures fertilized with 120 $\mathrm{kg} \mathrm{N} /$ ha. Grass and Forage Science, v. 75, p. 28-36, 2020. DOI: https://doi.org/10.1111/gfs.12463

PRIMAVESI. A. C.; PRIMAVESI, O.; CORRÊEA, L. A.; CANTARELLA, H.; SILVA, A. G.; FREITAS, A. R.; VIVALDI, L. J. Adubação Nitrogenada em Capim-
Coastcross: Efeitos na extração de nutrientes e recuperação aparente do nitrogênio. Revista Brasileira de Zootecnia, v. 33, n. 1, p. 68-78, 2004a. Disponível em: https://www.scielo.br/pdf/rbz/v33n1/a10v33n1.pdf.

PRIMAVESI, O.; PRIMAVESI, A. C.; CORRÊA, L. A.; ARMELIN, M. J.; FREITAS, A. R. Calagem em pastagem de Brachiaria decumbens recuperada com adubação nitrogenada em cobertura. São Carlos: Embrapa Pecuária Sudeste, 2004b. 32 p. Disponível em: https://www.infoteca.cnptia.embrapa.br/infoteca/bitstr eam/doc/46362/1/Circular37.pdf.

PRIMAVESI. A. C.; PRIMAVESI, O.; CORRÊEA, L. A.; SILVA, A. G.; CANTARELLA. H. Nutrientes na fitomassa de capim-marandu em função de fontes e doses de nitrogênio. Ciência e Agrotecnologia, v. 30, n. 3, p. 562-568, 2006. Disponível em: https://www.scielo.br/pdf/cagro/v30n3/v30n3a24.pdf

RAMOS, N. P.; YAMAGUCHI, C. S.; PIRES, A. M. M.; ROSSETTO, R.; POSSENTI, R. A.; PACKER, A. P.; CABRAL, O. M. R.; ANDRADE, C. A. Decomposição de palha de cana-de-açúcar recolhida em diferentes níveis após a colheita mecânica. Pesquisa Agropecuária Brasileira, v. 51, n. 9, p. 1492-1500, 2016. DOI: https://doi.org/10.1590/S0100-204X2016000900048.

SALES, K. C.; CABRAL, C. E. A.; ABREU, J. G.; BARROS, L. V.; SILVA, F. G.; CABRAL, C. H. A.; SANTOS, A. L. M.; SILVA JUNIOR, C. A.; CAMPOS FILHO, J. B. What is the maximum nitrogen in marandu palisadegrass fertilization? Grassland Science, v. 66, p. 153-160, 2020. DOI: https://doi.org/10.1111/grs.12266.

SANTOS, L. F. M.; LAPAZ, A. M.; TOMAZ, R. S.; LIRA, M. V. S.; MOREIRA, A.; REIS, A. R.; HEINRICHS, R. Evaluation of sulfur source and dose on the nutritional state and production of piatã forage. Semina: Ciências Agrárias, v. 40, n. 3, p. 1237-1248, 2019. DOI: https://doi.org/10.5433/1679-0359.2019v40n3p1237.

SCHMIDT, F.; MONTEIRA, F. A. Sulphur supply affects morphology, growth and nutritional status of Tanzania Guinea grass and Mineirão stylo. Grass and Forage Science, v. 70, p. 439-450, 2015. DOI: https://doi.org/10.1111/gfs.12122.

SILVA, B. S.; SILVA, R. B.; GONÇALVES, L. G. N.; SILVA, P. R.; PAIMEL, A. C. C.; ARAUJO, A. M.; CABRAL, C. E. A.; CABRAL, C. H. A. Adubação com enxofre na implantação e manutenção do capim Piatã. In: SIMPÓSIO INTERNACIONAL SOBRE SUSTENTABILIDADE DA BOVINOCULTURA DE LEITE E CORTE NO CERRADO, 1, 2019, Campo Grande. Anais... Campo Grande: UFMS, SOBAMA, $2019 . \quad$ Disponível em: https://simbovcerrado.ufms.br/files/2020/07/Anais_si mposio.pdf

SOARES, W.; LOBATO, E.; SOUSA, D. M. G.; VILELA, L. Adubação fosfatada para manutenção de pastagem de Brachiaria decumbens no Cerrado. Planaltina: Embrapa Cerrados, 2001. 5p. Disponível em: https://www.infoteca.cnptia.embrapa.br/infoteca/bitstr eam/doc/566167/1/comtec53.pdf.

SOARES FILHO, C. V.; CECATO, U.; RIBEIRO, O. L.; ROMA, F. C. C.; JOBIM, C. C.; BELONI, T.; PERRI, S. H. V. Root system and root and stem base organic reserves of pasture Tanzania grass fertilizer with nitrogen under grazing. Semina: Ciências Agrárias, v. 34, n. 5, p. 
2415-2426, 2013. Disponível em: https: / / www.redalyc.org/articulo.oa?id=445744135029.

SOUSA, D. M. G.; MARTHA JÚNIOR, G. B.; VILELA, L. Adubação fosfatada. In: MARTHA JUNIOR, G. B.; VILELA, L.; SOUSA, D. M. G. Cerrado: uso eficiente de corretivos e fertilizantes em pastagens. Planaltina: EMBRAPA Cerrados, 2007. p. 145-177. Disponível em: https://www.infoteca.cnptia.embrapa.br/infoteca/bitstr eam/doc/1113533/1/Livro.pdf.

SOUSA, D. M. G.; LOBATO, E.; REIN, T. A. Uso de gesso agrícola nos solos do Cerrado. Planaltina: Embrapa Cerrados, 2005. 18p. Disponível em: https://www.infoteca.cnptia.embrapa.br/bitstream/doc /568533/1/cirtec32.pdf.

TASCA, F. A.; ERNANI, P. R.; ROGERI, D. A.; GATIBONI, L. C.; CASSOL, P. C. Volatilização de amônia do solo após a aplicação de ureia convencional ou com inibidor de uréase. Revista Brasileira de Ciência do Solo, v. 35, n. 2, p. 493-502, 2011. DOI: https://doi.org/10.1590/S0100-06832011000200018.

TEIXEIRA, P. C.; MESQUITA, I. L.; MACEDO, S. T.; TEIXEIRA, W. G.; LIMA, W. A. A. Resposta de vetiver à aplicação de calcário e fósforo em três classes de solo. Revista Brasileira de Engenharia Agrícola e Ambiental, v. 19, n. 2, p. 99-105, 2015. DOI: http:/ /dx.doi.org/10.1590/18071929/agriambi.v19n2p99-105.

VILELA, L.; MARTHA JUNIOR, G. B.; SOUSA, D. M. G. Adubação potássica e com micronutrientes. In: MARTHA JUNIOR, G. B.; VILELA, L.; SOUSA, D. M. G. Cerrado: uso eficiente de corretivos e fertilizantes em pastagens. Planaltina: EMBRAPA Cerrados, 2007b. p. 179-188. Disponível em: https://www.infoteca.cnptia.embrapa.br/infoteca/bitstr eam/doc/1113533/1/Livro.pdf.

VILELA, L.; MARTHA JUNIOR, G. B.; SOUSA, D. M. G. Adubação com enxofre e gessagem. In: MARTHA JUNIOR, G. B.; VILELA, L.; SOUSA, D. M. G. Cerrado: uso eficiente de corretivos e fertilizantes em pastagens. Planaltina: EMBRAPA Cerrados, 2007a. p. 107-116. Disponível em: https://www.infoteca.cnptia.embrapa.br/infoteca/bitstr eam/doc/1113533/1/Livro.pdf. 